\title{
Perancangan Clothing dengan Desain Khas Lombok sebagai Suvenir
}

\author{
Baiq Nindiastuty Fitrimaghfira dan R. Eka Rizkiantono \\ Departemen Desain Produk Industri, Fakultas Arsitektur Desain dan Perencanaan, \\ Institut Teknologi Sepuluh Nopember (ITS) \\ e-mail: ekaindian007@gmail.com
}

\begin{abstract}
Abstrak-Wisatawan Pulau Lombok membutuhkan suvenir pakaian dengan keunikan dan kekhasan pulau Lombok yang memiliki daya tarik. Suvenir pakaian yang berkembang saat ini memiliki tema dan karakteristik desain yang cenderung sama dengan yang lain. Desain yang ditawarkan menarik tetapi belum menonjolkan khas pulau Lombok. Oleh karena itu dibutuhkan desain suvenir pakaian yang berbeda dari suvenir yang sudah ada. Dengan menggunakan data primer dan sekunder yang diperoleh dari metode depth interview Dinas Pariwisata dan Kebudayaan kota Mataram dan pemilik sasaku Lombok, observasi, kajian literatur bersumber pada buku pedoman statistik kepariwisataan, buku fashion dan sejarah gaya desain sehingga mendapatkan konsep Authentic Lombok. Dengan melakukan explorasi berbagai gaya desain yang mengacu pada tren desain vintage salah satunya Artdeco. Artdeco merupakan gaya desain yang menggunakan unsur geometris untuk membentuk objek. Konsep authentic lombok menampilkan kebudayaan seperti gendang beleq, tari oncer, perang peresean yang diaplikasikan pada kaos, scarf dan kemeja. Kemudian wisata alam seperti pantai batu bolong dengan kegiatan olahraga bersepeda pada kaos dan kuliner. Lombok seperti sate bulayak pada outer dan syal. Selain itu edisi desain peta daerah lombok yang menunjukkan lokas2. wisata. Suvenir pakaian dengan tema authentic lombok sudah menggambarkan khas lombok. Warna warna yang digunakaß. pada desain menarik disertai bahan pakaian yang lembut dan hasil cetak yang sesuai. Beberapa desain perlu dikembangkan dengan menggunakan tren desain yang lain.
\end{abstract}

Kata Kunci-Souvenir, Khas Lombok, Pakaian.

\section{PENDAHULUAN}

$\mathrm{M}$ ENURUT sumber dinas pariwisata Provinsi NTB. berdasarkan grafik perhitungan wisatawan domestik maupun asing, pertumbuhan kunjungam pariwisata ke NTB meningkat cukup cepat. Diawal pemerintahan gubernur dua periode atau tepatnya tahurs. 2008 kunjungan wisatawan 544.501 orang yang kemudian meningkat pada 2015 menjadi 2.210.527 [1]. Didalam kegiatan pariwisata, dapat disimpulkan bahwa komponen wisata dipengaruhi oleh tiga faktor yaitu something to see, something to do, something to buy. something to buy terkait dengan suvenir khas yang dibeli di daerah tujuan wisata sebagai memorabilia pribadi wisatawan. Dalam ketiga komponen tersebut, mempromosikan khas Lombok dapat masuk melalui something to buy dengan menciptakan produk-produk inovatif khas Lombok. Terdapat berbagai macam suvenir khas Lombok yang diminati oleh masyarakat diantaranya kain songket dan tenun sasak, dodol rumput laut, mutiara lombok, hasil kerajinan tangan seperti gerabah dan kendi, aksesoris, dan kaos. Menurut data yang telah dikumpulkan oleh media kompas.com salah satu suvenir yang wajib dibeli masyarakat adalah kaos Lombok. Hal ini dikarenakan selain memiliki harga yang murah juga dapat menunjukkan bahwa si wisatawan pernah mengunjungi tempat tertentu. Terdapat banyak wilayah yang menjual suvenir pakaian Lombok tetapi sebagian besar memiliki jenis desain dan motif yang cenderung mirip antara yang satu dengan yang lainnya. Motif pada pakaian suvenir yang dijual di pasar pada umumnya menggambarkan corak cicak, budaya lombok seperti peresean, dan wisata pantai di Lombok. Produk yang ditawarkan pada merk lokal adalah hanya kaos tanpa menjual produk lain dibidang fashion . mengutip dari pernyataan Jeny Tjahyawati bahwa salah satu hal yang mempengaruhi sektor pariwisata adalah fashion yang merupakan hasil kreativitas desainer Indonesia. Fashion tidak hanya kaos melainkan produk lain yang dikenakan beserta aksesorisnya. Sehingga diperlukan pengembangan pada produk lain seperti topi, scraf, kemeja, dress dsb untuk dijadikan suvenir.

\section{A. Identifikasi masalah}

Desain pada suvenir Lombok belum beragam, sebagian besar mengangkat wisata alam dan motif cicak atau tokek.

Seluruh daerah wisata dilombok memiliki desain suvenir yang cenderung sama.

Diperlukan desain pakaian sebagai suvenir dengan kualitas dan kriteria yang diinginkan pasar.

\section{B. Rumusan masalah}

Bagaimana cara merancang suvenir dalam bentuk pakaian dengan desain kekhasan pulau Lombok untuk wisatawan?

\section{Batasan masalah}

Perancangan fokus membahas mengenai suvenir berupa clothing yaitu kaos dan pendamping pakaian lainnya.

Tidak membahas mengenai suvenir lain yang tidak berhubungan dengan pakaian.

Studi lokasi penelitian khusus dilakukan di daerah pulau Lombok.

\section{Maksud dan Tujuan}

. Merancang desain suvenir pakaian mengenai keunikan dan kehasan pulau Lombok yang memiliki daya tarik dan dapat bermanfaat terhadap wisatawan.

. Memberikan tampilan visual yang menarik pada suvenir dan dapat menjadi kebanggan masyarakat pulau Lombok yang sesuai dengan kriteria target pasar.

\section{METODE PENELITIAN}

\section{A. Metode Pengumpulan Data}

Metode pengumpulan data yang digunakan oleh penulis adalah sebagai berikut:

1) Data Primer

a. Observasi 
Observasi ini dilakukan langsung oleh peneliti pada tanggal 04 desember 2017.

b. Dokumentasi Foto

Data berupa gambar didapat oleh penulis dari dengan mengambil beberapa foto model pakaian sebagai oleh oleh atau suvenir.

c. Depth Interview

Melakukan wawancara mendalam dengan beberapapihak yang berkaitan dengan subjek penelitian diantaranya adalah:

1. Ibu Utria Salim sebagai Kepala seksi kerjasama bidang pemasaran Dinas Pariwisata dan Kebudayaan. Membahas beberapa pertanyaan mengenai tempat tempat kuliner khas lombok yang paling banyak digemari, penjualan dan karakteristik suvenir pakaian di Lombok

2. Mantra Ardhana seorang seniman lokal sekaligus desainer produk suvenir dan oleh oleh brand sasaku. Menanyakan permasalahan yang tidak hanya sekedar minimnya pengetahuan wisatawan mengenai kuliner khas namun lebih dari itu menyangkut permasalahan lain dalam ruang lingkup kuliner dan suvenir.

3. Kuisioner

Kuesioner disebarkan melalui internet (google forms)

\section{B. Proses Perancangan}

Setelah menemukan fenomena, penulis merumuskan permasalahan yang dilanjutkan dengan mencari data terkait dengan subjek perancangan. Pencarian data dilakukan untuk mendapatkan hasil dan analisa dalam merumuskan konsep desain yaitu tema yang diangkat. Selain itu untuk mendapatkan kriteria desain dan segmentasi. Berdasarkan ketiga hal tersebut dilakukan eksperimen desain untuk menemukan gaya desain yang tepat, layout dan model pakaian. Setelah desain dari beberapa konten telah dibuat kemudian diimplementasikan pada pakaian.

\section{HASIL DAN KESMPULAN}

\section{A. Analisa dan Hasil Pengumpulan Data}

1. Depth Interview dengan Ibu Utria Salim sebagai Kepala seksi kerjasama bidang pemasaran Dinas Pariwisata dan Kebudayaan. Peneliti mendapatkan 4 hal yang sangat mendukung pariwisata yaitu keindahan alam, budaya, sport tourism dan kuliner. Beliau juga menjelaskan bahwa banyak suvenir di bidang retail yang bagus dan menarik namun belum ada yang menunjukkan keunikan dan khasan Lombok.

2. Depth Interview Mantra Ardhana seorang seniman lokal sekaligus desainer produk suvenir dan oleh oleh brand sasaku. . Beliau juga mengatakan bahwa karakter lucu dan kata kata jenaka disingkirkan dari list gaya gambar sebab akan menurunkan tingkat segmen pembelinya.

3. Hasil Kuisioner terhadap 100 responden adalah mereka memilih souvenir clothing seperti kaos, kemeja dan kain khas yaitu sebanyak $50 \%$. Menyukai desain pakaian dengan karakter yang etnik, unik dan colorful.

\section{B. Karakteristik Target Audiens}

1. Demografis

Usia : usia 22- 35 tahun

Jenis kelamin : laki-laki dan perempuan
Domisili : domestik dan mancanegara

Penghasilan perbulan : $\geq \operatorname{Rp} 1.500 .000$ perbulan

Pendidikan terakhir : S1

Strata sosial : kelas atas dan menengah

Pekerjaan : mahasiswa, wiraswasta, pegawai negeri, pegawai swasta.

2. Geografis

Masyarakat yang bertempat tinggal di Lombok atau pernah mengunjungi pulau Lombok sebagai destinasi wisata.

3. Psikografis

a. Suka berpergian ( Travelling)

b. Menyukai wisata alam dan kegiatan yang ada di dalamnya seperti senggigi, gili Lombok dsb.

c. Menyukai kebudayaan dan seni daerah lokal.

d. Menyukai perkembangan fashion.

e. Mengikuti perkembangan teknologi.

\section{PROSES DAN IMPLEMENTASI DESAIN}

\section{A. Konsep Desain}

Berdasarkan hasil dan analisa ditentukan konsep desain yaitu Authentic Lombok. Makna dari keyword Authentic of Lombok adalah seagala sesuatu mengenai pulau Lombok yang menjadi khas, unik dan original (asli).

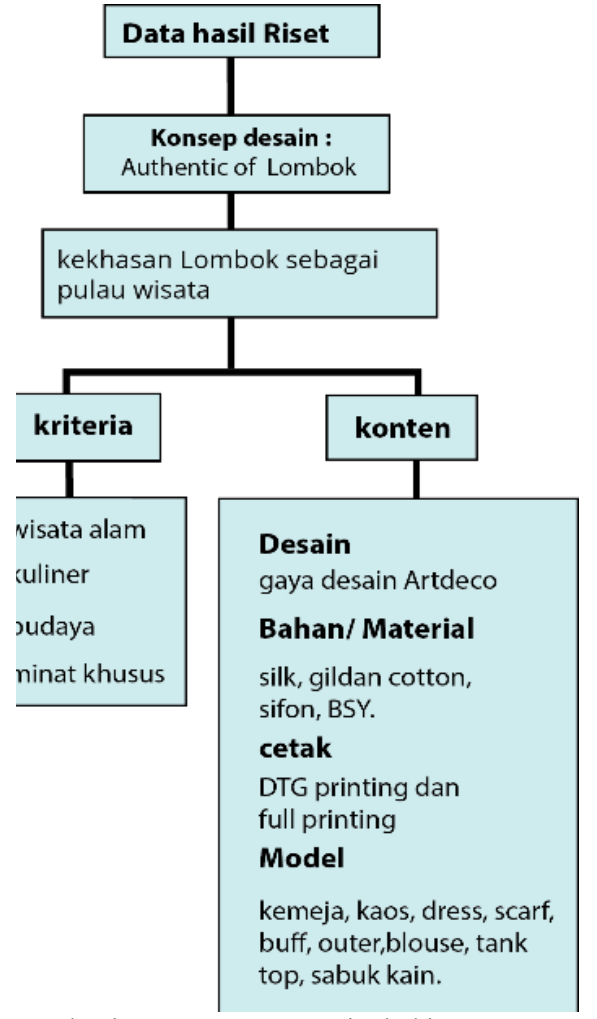

Bagan 1. Konsep desain merancang souvenir clothing.

Setiap daerah memiliki kekhasan dan keunikan masing masing di berbagai bidang diantaranya wisata alam seperti batu payung, kebudayaan seperti perang peresean, kuliner ayam taliwang dan minat khusus berwisata seperti surfing. Konsep desain tersebut diimplementasikan dengan gaya Artdeco melalui printing digital pada pakaian kemeja, kaos, dress, scarf, buff, outer,blouse, tanktop, sabuk kain.

1. Gaya desain

Berdasarkan pengamatan mengenai gaya gambar yang sedang tren atau populer di tahun 2018 adalah gaya yang 
pernah populer pada masa lalu. sehingga gaya gambar yang digunakan akan berputar kembali mengikuti perjalanan sejarah desain.

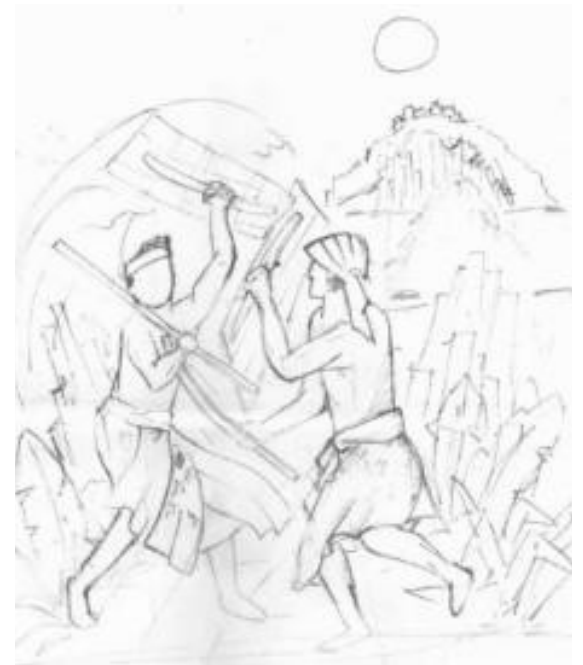

Gambar 1. Sketsa perang peresean.

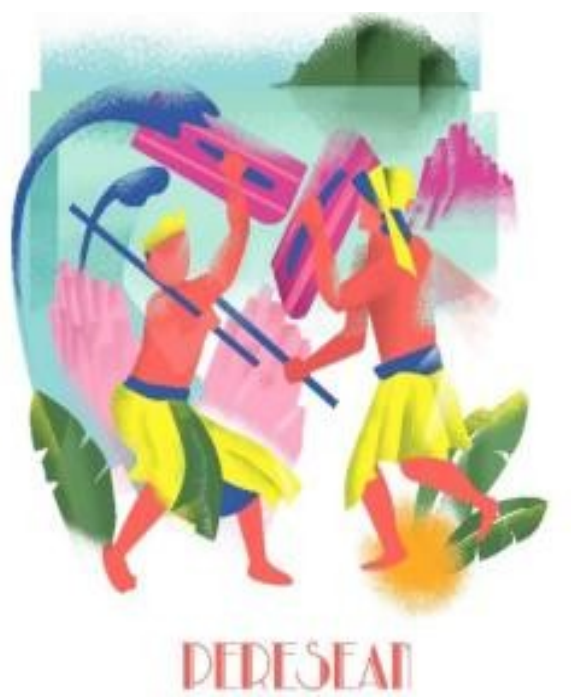

Gambar 2. Illustrasi perang peresean.

Selain kegiatan kebudayaan seperti pada Gambar diatas, artdeco juga diterapkan pada kuliner Lombok dengan layot tampak dari atas.

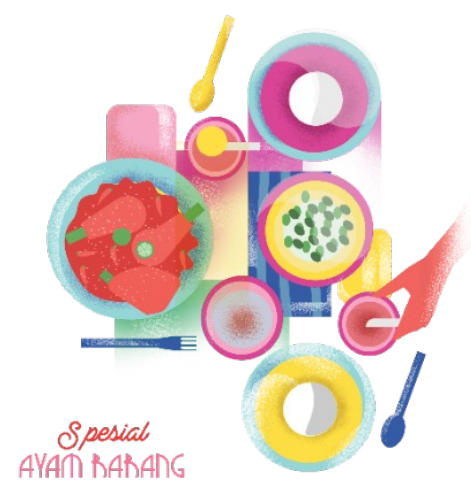

Gambar 3. Illustrasi makanan ayam rarang.

Gaya gambar Artdeco yang merupakan salah satu gaya gambar modern populer populer dari 1920 hingga 1939 [2]. Ciri ciri dari gaya artdeco adalah terbentuk dari bidang yang abstrak dan geometris seperti misalnya bentuk tangga, segitiga dan lingkaran terbuka, menggunakan warna warna yang kuat.

\section{Typhografi}

Jenis Typhografi yang digunakan disesuaikan dengan gaya Artdeco yaitu font yang tidak bertangkai dan font script. Karakter san serif dipilih karena memiliki karakter yang modern [3].

Tabel 1

Jenis Font yang digunakan pada perancangan

\begin{tabular}{|c|c|c|}
\hline Nama font & Jenis & Contoh \\
\hline Park Lane NF & dekoratif & $\begin{array}{c}\text { Authentic } \\
\text { Lombok }\end{array}$ \\
\hline Besters Supply & script & $\begin{array}{c}\text { Authentic } \\
\text { Lombok }\end{array}$ \\
\hline Grenadier NF & dekoratif & $\begin{array}{c}\text { Authentic } \\
\text { Lombok }\end{array}$ \\
\hline Monserat & San serif & $\begin{array}{c}\text { Authentic } \\
\text { Lombok }\end{array}$ \\
\hline
\end{tabular}

\section{Warna}

Warna yang diterapkan pada desain pakaian dengan mengangkat kekhasan pulau Lombok adalah warna warna tropical yang cenderung berwarna biru laut, hijau, kuning ditambah unsur unsur warna etnik pada pewarna alami kain songket suku sasak.

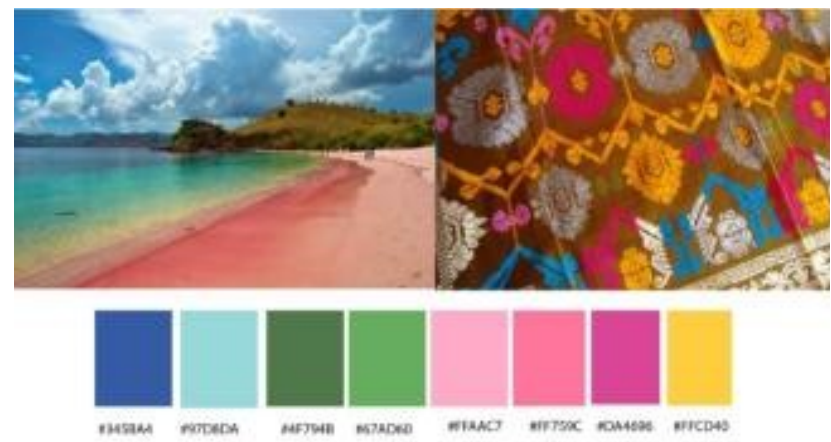

Gambar 4. colour pallete.

\section{Layout}

Pada perancangan suvenir clothing dibidang clothing atau pakaian terdapat aturan tata letak gambar atau tulisan pada objek suvenir. Berikut ini adalah salah satu tata letak (layout) pada suvenir clothing pada kaos lengan panjang.

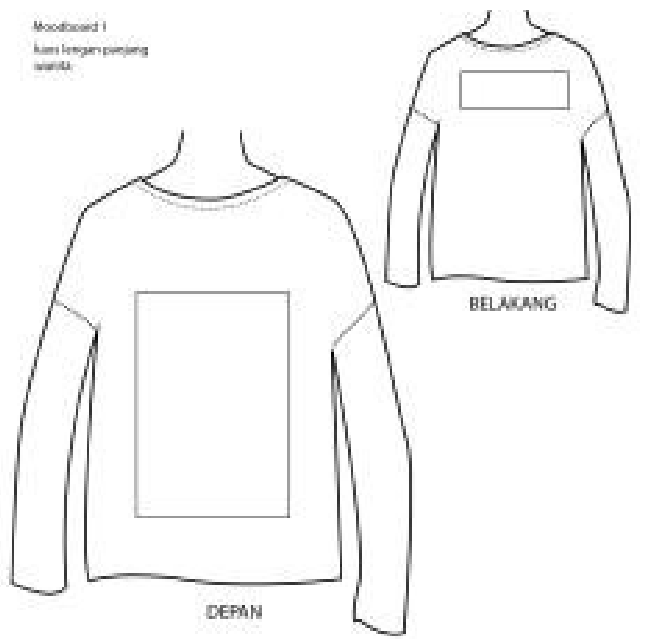

Gambar 5. Layout kaos lengan panjang. 
Selain itu digunakan layout full print pada pakaian seperti dress, kemeja, outer dan aksesoris pakaian. Jakob schlaepfer mengatakan bahwa print digital pada fashion membuat objek desain menjadi terlihat lebih detail dan menarik perhatian [4].

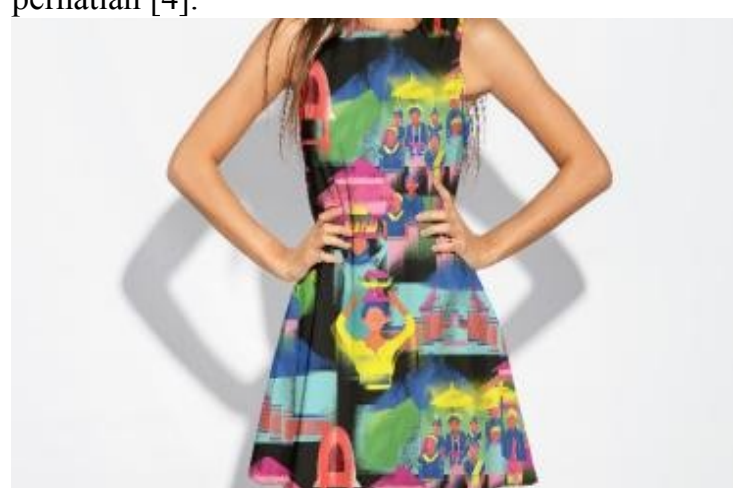

Gambar 6. Layout dress full print.

B. Proses Desain dan Implementasi

1. Kebudayaan
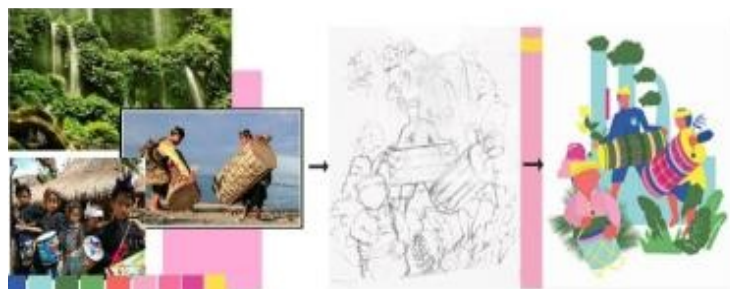

Gambar 7. Proses desain gendang beleq.

Gambar diatas merupakan proses desain kebudayaan dan wisata lombok salah satunya gendang beleq dimulai dari pengumpulan ide bentuk gambar kemudian dilakukan stilasi bentuk artdeco dengan sketsa. Setelah proses sketsa kemudian gambar dibawa ke software pembuat vektor menjadi bentuk digital dengan warna yang sudah ditentukan sesuai moodboard. Setelah vektor selesai kemudian finishing melalui photoshop untuk memberikan kesan shading dan grain pada Gambar.

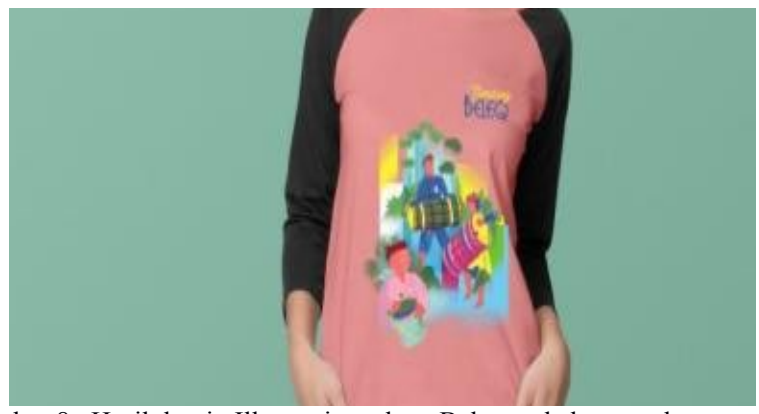

Gambar 8. Hasil desain Illustrasi gendang Beleq pada kaos reglan.

Selain Gendang Beleq desain yang dibuat mengangkat tema kebudayaan diantaranya perang peresean, perang topat, budaya suku bayan, adat sasak, budaya tenun desa sade, bau nyale dan adat Nyongkolan.

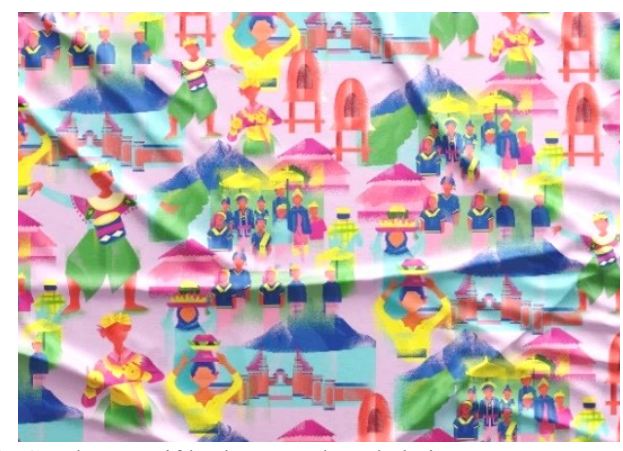

Gambar 9. Gambar Motif budaya sasak pada kain.

Beberapa karakter kebudayaan dibuat menjadi motif kain digunakan untuk aksesoris pakaian, outer, scarf dan sebagainya.

1. Wisata Lombok

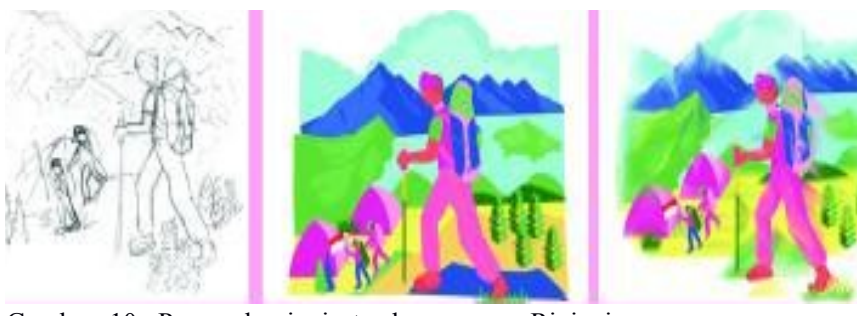

Gambar 10. Proses desai wisata alam gunung Rinjani.

Gambar diatas merupakan proses desain tradisi illustrasi danau segara anak, rinjani. Proses dan tahapan sama dengan poin sebelumnya. Selain gunung rinjani, wisata alam lainnya yang diamplikasikan adalah pantai batu bolong, pantai selong belanak dan air terjun benang kelambu.

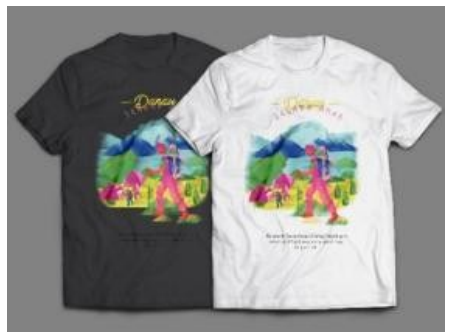

Gambar 11. Implementasi gambar gunung rinjani pada kaos.

Gambar diatas merupakan hasil implementasi visual desain Gunung Rinjani dan kegiatan mendaki pada kaos reglan hitam dan putih. Bahan yang digunakan adalah katun combed 20s [5].

2. Peta Wisata Pulau Lombok

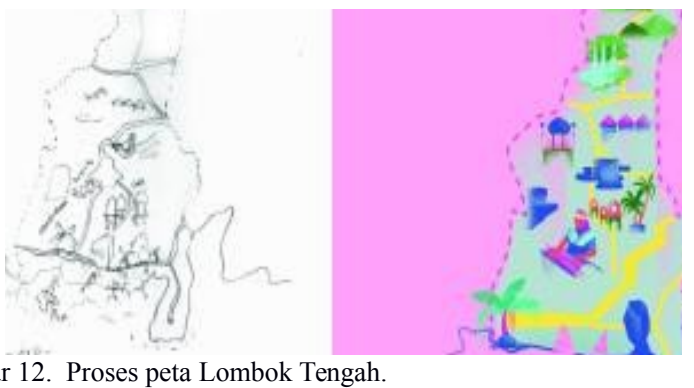

Gambar 12. Proses peta Lombok Tengah.

Gambar diatas merupakan proses Desain illusrasi lombok tengah. Dilakukan explorasi bentuk dengan sketsa (gambar paling kiri). Kemudian dibuat menjadi vektor (gambar paling kanan). Proses dan tahapan sama dengan poin sebelumnya. 


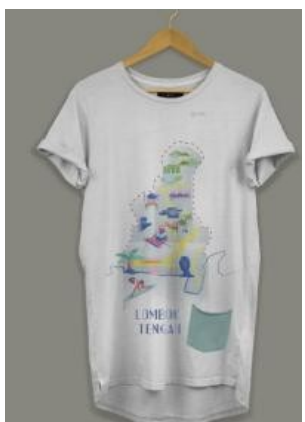

Gambar 13. Kaos Illustrasi Peta Lombok Tengah.

Kumpulan Edisi peta kabupaten/kota di lombok dengan arah dan petunjuk wisata. Edisi ini memberikan kemudahan kepada wisatawan dalam mengenal dan bertanya mengena tempat wisata dilombok kepada masyarakat lokal terpencil yang tidak satu bahasa. Contohnya wisatawan dari prancis bertanya lokasi kepada penduduk asli sasak yang sulit berbahasa inggris.

4. Makanan khas Lombok
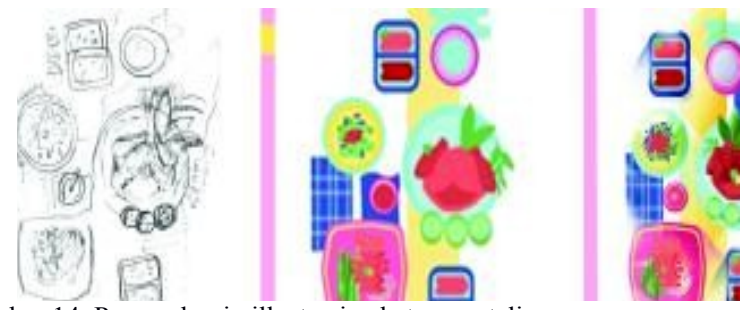

Gambar 14. Proses desain illustrasi paket ayam taliwang.

Proses desain illustrasi paket ayam taliwang dan sama dengan poin sebelumnya. Persepektif illustrasi makanan tampak dari atas. Selain ayam taliwang, kuliner yang diangkat diantaranya sate bulayak, paket ayam rarang dan aneka jajanan khas Lombok.

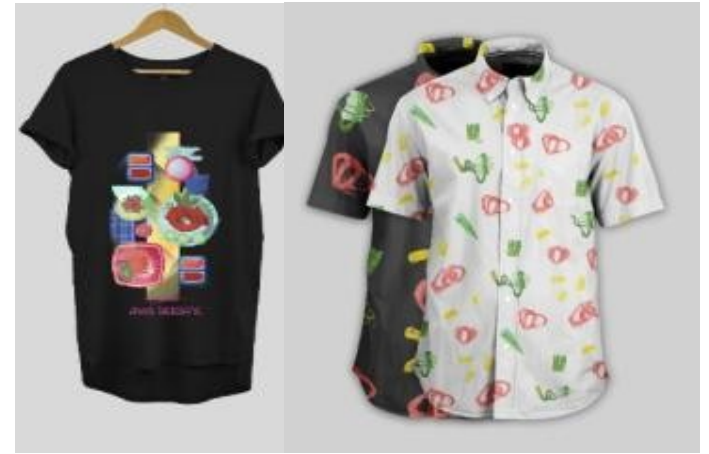

Gambar 15. Implementasi ilustrasi kuliner ayam taliwang pada kaos (kiri) illustrasi jajan pada kemeja (kanan).

\section{Variasi Monokrom}

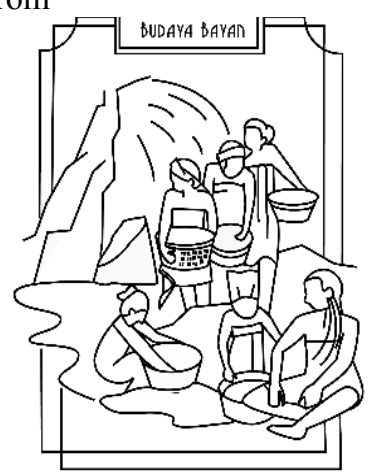

Gambar 16. Illustrasi Monokrom.

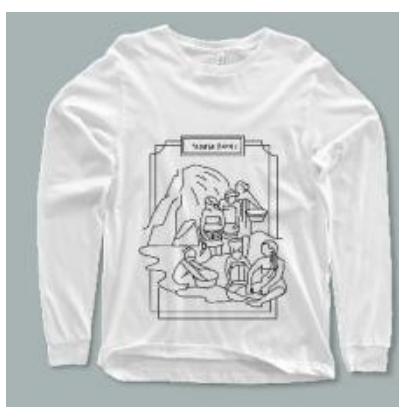

Gambar 17. Implementsilllustrasi pantai monokrom pada kaos.

Berdasarkan hasil survey kuisioner terdapat beberapa segmen yang menyukai warna monokrom yaitu $2 \%$ selain warna cerah. Warna monokrom memberikan kesan yang sederhana dan santai.

\section{Konsep Bisnis Dan Produksi}

Setelah perancangan pada produk dapat diimplementasikan pada pakaian sesuai rancangan kemudian dibutuhkan sistem bisnis dan produksi agar proses penjualan berjalan lancar.

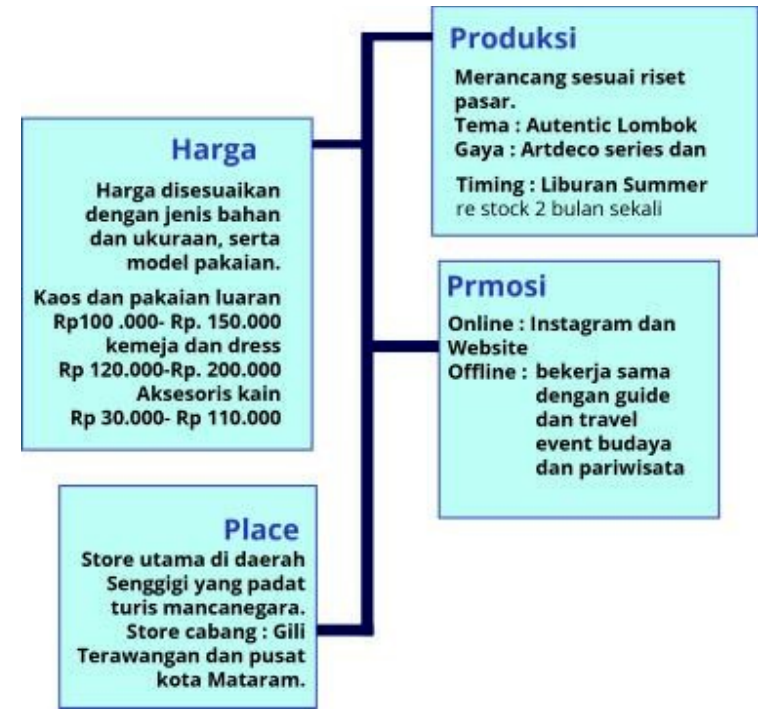

Bagan 2. Konsep bisnis dan produksi.

Produk akan di produksi 2 bulan sekali untuk produk tertentu dan launching pertama pada awal liburan summer. Harga yang dikenakan pada pakaian sekitar Rp. 100.000 hingga Rp. 200.000. Toko utama berada di Senggigi yang padat dengan turis asing dan lokal. Store cabang di gili terawangan dan kota mataram sedangkan promosi dilakukan secara online dan transaksi secara offline bekerja sama dengan travel dan dinas kebudayaan dan pariwisata.

\section{Kemasan}

1. Kemasan umum

Kemasan umum adalah kemasan untuk pembelian produk bukan produk ekslusif. 


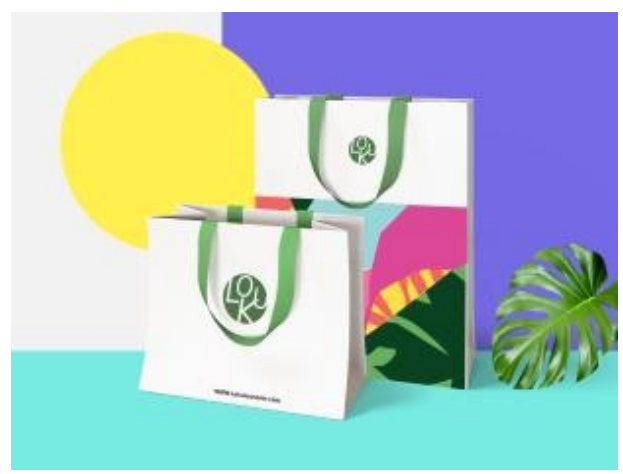

Gambar 18. Kemasan umum.

Kemasan umum yang mampu memuat beberapa jumlah baju. Terdapat dua ukuran paper bag yaitu big size dan mini.

2. Kemasan Khusus

Kemasan khusus adalah kemasan untuk pembelian produk eksklusif. Produk exclusif adalah produk yang memiliki bahan dan desain yang berbeda dan harga yang lebih mahal dari produk lainnya.

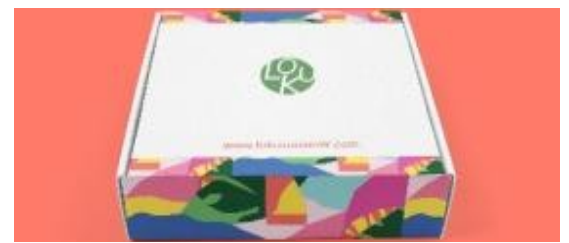

Gambar 19. Kemasan khusus.

\section{KESIMPULAN}

Desain pada pakaian suvenir Lombok memiliki Warna warna yang menarik serta konten pada pakaian sudah menunjukkan khas Pulau Lombok. Model pakaian yang bervariasi membuat suvenir ini menjadi marketable. Jenis kaos dan sablon atau printing yang digunakan sesuai, bahan halus sehingga nyaman untuk digunakan, warna dan gradasi terlihat cerah. Untuk kedepannya beberapa desain perlu dikembangkan seperti desain visual menjadi versi sederhana, model pakaian, layout desain pada pakaian dan explorasi full print.

\section{DAFTAR PUSTAKA}

[1] Dinas Pariwisata Provinsi Nusa Tenggara Barat, "Kajian Analisa Pasar Potensial NTB tahun 2017," 2017.

[2] S. Heller and S. Chwast, Graphic Design: From Victorian To Digital. New York: Harry N. Abrams, Incorporated, 2000.

[3] M. Krysinski, The Art of Type and Typography: Explorations in Use and Practice. New York: Rountladge, 2018.

[4] S. Clarke, Print: Fashion, Interior, Art. United Kingdom: Laurence King Publishing Ltd., 2014.

[5] T. Neko, "Macam- Macam Jenis Kain dan Sifat," 2016. [Online]. Available: https://tekoneko.net/macam-macam-kain. 